\title{
Evaluation of percutaneous annuloplasty for treatment of functional mitral regurgitation: A retrospective study
}

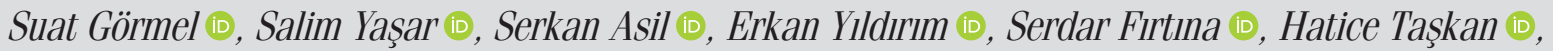 \\ Mustafa Köklü (D), Yalçın Gökoğlan (D), Barış Buğan (D, Ayşe Saatçi Yaşar (i), Hasan Kutsi Kabul Đ, Murat Çelik (D), \\ Uygar Çăgdaş Yüksel (D), Cem Barçın (D) \\ Department of Cardiology, Gülhane Training and Research Hospital; Ankara-Turkey
}

\section{ABSTRACT}

Objective: The management of severe functional mitral regurgitation (FMR) in patients with heart failure (HF) and low ejection fraction is controversial, but percutaneous transcatheter procedures are promising. In this retrospective analysis, we aimed to assess the efficacy of the Carillon Mitral Contour System in patients with "inoperable" severe FMR.

Methods: Seventy three patients (mean age 66.89, range 31-90 years) with congestive heart failure (CHF), severe FMR, and reduced ejection fraction $(<35 \%)$ who underwent Carillon device implantation were examined. The study group consisted of patients with successfully implanted devices whereas the control group comprised patients in whom the device could not be deployed. The primary endpoint was combined allcause mortality and first hospitalization for HF (whichever came first).

Results: The median $(01,03)$ follow-up was $31(11-49)$ months. The device was deployed successfully in 50 patients (implant group) and not in 23 patients (non-implant group). Both the primary endpoint and all-cause mortality were lower in the "implant" group, but the differences were not significant. The median to primary endpoint was 21 [95\% confidence interval (Cl) 8.8-33.2] and six (95\% Cl 0.1-11.9) months for the implant group and the non-implant group, respectively $(\mathrm{p}=0.078)$.

Conclusion: Carillon Mitral Contour System implantation is a safe procedure and results in the reduction of all-cause mortality and combined endpoint of mortality and hospitalizations for HF in inoperable patients with severe FMR and low ejection fraction, although the difference did not meet the significance level.

Keywords: functional mitral regurgitation, heart failure, percutaneous mitral annuloplasty

Cite this article as: Görmel S, Yaşar S, Asil S, Yıldırım E, Fırtına S, Taşkan H, et al. Evaluation of percutaneous annuloplasty for treatment of functional mitral regurgitation: A retrospective study. Anatol J Cardiol 2021; 25: 505-11.

\section{Introduction}

Functional mitral regurgitation (FMR) is a common condition in dilated cardiomyopathy mostly as a result of distorted left ventricular geometry (1). The increase in hemodynamic stress on the failing left ventricle (LV) causes higher filling pressures, progressive LV dilation, progressive systolic dysfunction, and lower cardiac output $(2,3)$. FMR increases mortality and decreases functional capacity. There are only a few targeted treatment modalities available addressing FMR (4-6). Current guidelines indicate that patients with FMR, who are candidates for coronary artery bypass grafting, should undergo surgical mitral valve (MV) repair if feasible. In high-risk patients with FMR and low ejection fraction who are not candidates for revascuIarization, the current guidelines do not recommend surgical mitral repair $(7,8)$. Percutaneous transcatheter procedures for the treatment of severe MR are treatment options for patients who cannot undergo open MV surgery. Several catheter-based devices, such as the MitraClip (Abbott Vascular, Santa Clara CA, USA) and Carillon Mitral Contour System (Cardiac Dimensions, Kirkland, WA, USA), have been developed. The MitraClip device is the most common percutaneous device used to treat FMR with both CE and FDA grants. The Carillon Mitral Contour System, an indirect mitral annuloplasty device, is another CEmarked percutaneous device to treat FMR. The AMADEUS and TITAN trials demonstrated a significant reduction in FMR with

Address for Correspondence: Dr. Suat Görmel, Gülhane Eğitim ve Araştırma Hastanesi, Kardiyoloji Kliniği, Ankara-Türkiye

Phone: +90 5306911024 E-mail: suatgormel@yahoo.com

Accepted Date: 21.06.2021 Available Online Date: 29.06.2021

(C) Copyright 2021 by Turkish Society of Cardiology - Available online at www.anatoljcardiol.com DOI:10.5152/AnatolJCardiol.2021.54599 


\section{HIGHLIGHTS}

- The Carillon Mitral Contour System is an alternative and promising indirect mitral annuloplasty method for patients with heart failure (HF) with severe FMR and low ejection fraction; however, there is a lack of proof regarding the effect of this method on cardiovascular clinical endpoints.

- Although retrospective, this is one of the largest studies in this field in the literature and included more patients with advanced HF than other similar studies.

- The Carillon device showed a tendency to decrease allcause mortality and combined endpoint of mortality and hospitalization for HF in this population.

the Carillon device. Recently, the REDUCE-FMR trial showed promise for percutaneous annuloplasty for treatment of FMR in the US, and experts are waiting for the US pivotal trial for FDA approval (9-12). In this retrospective study, we sought to assess the effect of the Carillon Mitral Contour System on all-cause mortality and heart failure (HF) and hospitalization in patients with severe, inoperable FMR and low ejection fraction.

\section{Methods}

\section{Study design}

This is a single center study in which we retrospectively analyzed the results of 73 consecutive patients who underwent percutaneous Carillon Mitral Contour System deployment for severe FMR between 2013 and 2018. All the patients were deemed to be "surgically inoperable" (i.e. had prohibitive risk for mitral valve surgery) by the heart team. This is a condition necessary for Carillon system to be reimbursed by the National Social Security System.

Included patients were symptomatic [ $\geq \mathrm{New}$ York Heart Association (NYHA) class 2] with dilated ischemic or non-ischemic cardiomyopathy and had severe $(\geq 3+)$ MR with LV ejection fraction $<40 \%$. Patients were stable for at least one month at the time of the procedure after optimized guideline based medical therapy.

Patients who had primary abnormality of the mitral apparatus (degenerative MR) and/or cardiac resynchronization therapy (CRT) as well as who underwent percutaneous coronary intervention within the prior 30 days and/or myocardial infarction or coronary artery bypass graft surgery within the prior three months were excluded.

Patients were divided into two groups according to the "success" of the device implantation (implant group vs. non-implant group). Successful device implantation was defined as deployment of the device at the target locations in coronary sinus without any complication. Patients in whom the device was not able to be deployed for any reason were the "non-implanted" group (Fig. 1).

Primary endpoint was combined all-cause mortality and first hospitalization for HF (whichever came first). All-cause mortality was also evaluated as a secondary endpoint independently. The endpoint data were obtained from National Database of health and personnel communication with the patients and patients' relatives when needed. Procedural and in-hospital complications were retrieved from the patient files. The institutional ethics committee approved the study.

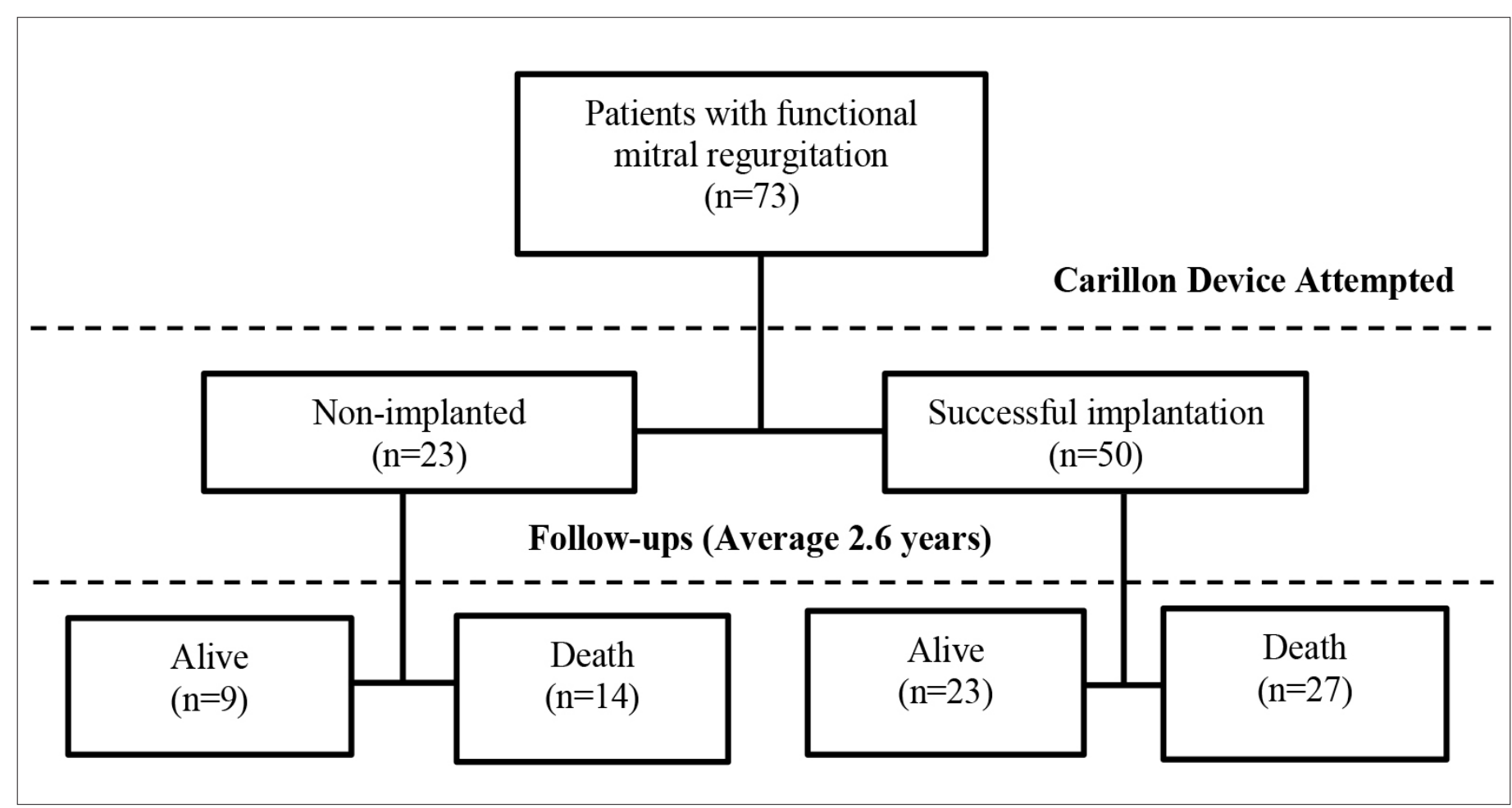

Figure 1. Flow diagram 


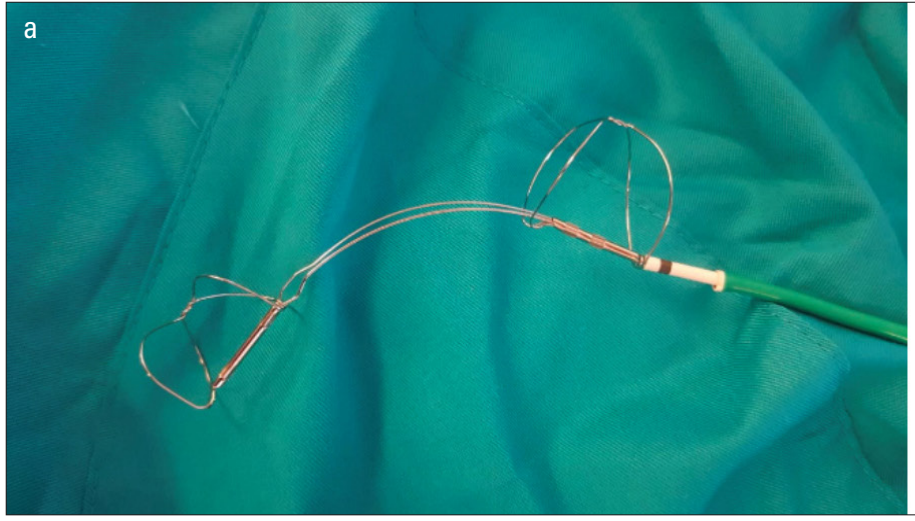

Figure 2. a) The Carillon device and, b) The Carillon delivery system

\section{Device implantation}

The distal and proximal nitinol anchors of the Carillon device are connected by a shaping ribbon that uses the heart's venous anatomy to encircle the mitral apparatus (Fig. 2a, 2b). There are a variety of anchor sizes (to accommodate different venous diameters) and device lengths of 60,70 , and $80 \mathrm{~mm}$. The procedures were performed under conscious sedation with fluoroscopic and transthoracic echocardiographic guidance. A $10 \mathrm{~F}$ venous access in the right internal jugular vein and 5 or $6 \mathrm{~F}$ arterial access via radial or femoral artery were obtained. From the internal jugular vein, the coronary sinus (CS) was engaged via a telescopic system made by a $9 \mathrm{~F}$ delivery catheter, a $6 \mathrm{~F}$ multipurpose catheter, and a 0.035" soft tip hydrophilic guidewire. Different diagnostic catheters were used at the discretion of the operator when needed. After advancement of the delivery catheter great cardiac vein/anterior interventricular vein junction, a marker catheter was placed in the CS through the delivery catheter. A venous angiogram was then performed, and the device size as well as the implant target locations were determined. The implant was then advanced through the delivery catheter, and a relatively oversized distal anchor was deployed at the target zone to provide stable anchoring. The entire delivery system was then pulled back approximately 4-6 cm under echocardiographic and fluoroscopic view. The degree of traction was guided by echocardiographic assessments to evaluate periprocedural changes in mitral regurgitation (MR) and mitral annular dimensions. Both left and right coronary angiograms were evaluated for a compression or a spasm in the circumflex or right coronary arteries. Once tissue plication was optimized, the proximal anchor was deployed near the CS ostium. The device could be captured and re-deployed with some modification in target zones at the discretion of the operator. In case of dissection in CS or compromise in coronary flow, the device was not implanted.

\section{Statistical analysis}

Continuous variables with normal distribution were expressed as mean \pm standard deviation and those without normal distribution as median (interquartile range). Normality of the continuous variables were checked with the Kolmogorov-Smirnov test. Between-group comparisons were performed using the Stu-

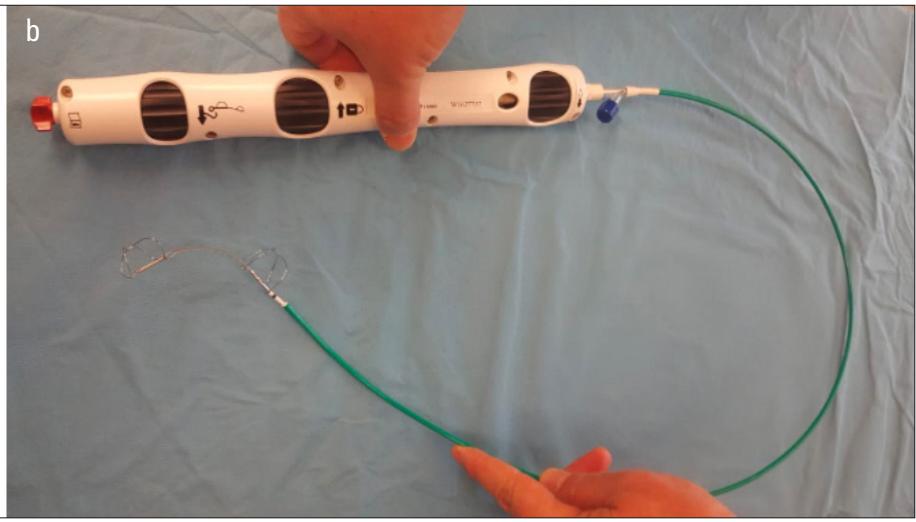

dent's t-test and Mann-Whitney $U$ test. Within group comparisons were performed with paired samples t-test. Categorical variables were expressed as number and percentage ( $n, \%)$. Binomial proportions were compared between treatment groups using Fisher exact test. Cox proportional hazard regression analysis was performed to assess the effect of sex and age in addition to the intervention status. A log-rank test was run to determine if there were differences in the survival distribution between the two groups. A two-sided $p$ value of $<0.05$ was considered significant in all analyses. Statistical analyses were performed using the Statistical Package for Social Sciences software for Windows (version 20.0; SPSS, Inc, Chicago, IL, USA).

\section{Results}

The baseline patient characteristics and echocardiographic parameters of the study population are shown in Tables 1 and 2.

The Carillon device was not able to be deployed in 23 (31.5\%) patients (non-implant group). The reason for "non-deployment" was unsuitable CS anatomy in 11 (5.1\%) patients, coronary artery compromise in nine $(12.3 \%)$ patients (all for circumflex artery), CS dissection in two $(2.7 \%)$ patients, and CS perforation causing procedural intolerability in one $(1.4 \%)$ patient. Only one patient died during the first 30 days follow-up because of ongoing hemodynamic instability as a result of CS perforation causing cardiac tamponade. Nevertheless, two other patients with CS perforation requiring pericardiocentesis were managed successfully. All the implanted Carillon devices were the older version (XE2), and we did not encounter any fracture during the follow-up. Table 3 depicts pre-procedural and post-procedural echocardiographic parameters of the implantation group. Accordingly, MR grade decreased from $3.5 \pm 0.5$ to $2.5 \pm 0.6$ $(p<0.001)$, and vena contracta decreased from $8.6 \pm 1.7$ to $5.6 \pm 1.9$ $(p<0.001)$ shortly after the procedure.

Patients with successful device implantation had a median survival time free from death of any cause and hospitalization for HF of 21.1 months [ $95 \%$ confidence interval (CI) 8.8 to 33.2 months]. This was longer than that of the non-implant group 6.0 months; $95 \% \mathrm{Cl}$ : 0.1 to 11.9 months), but the long rank test showed that this difference was not significant, $\chi^{2}=3.096$, 


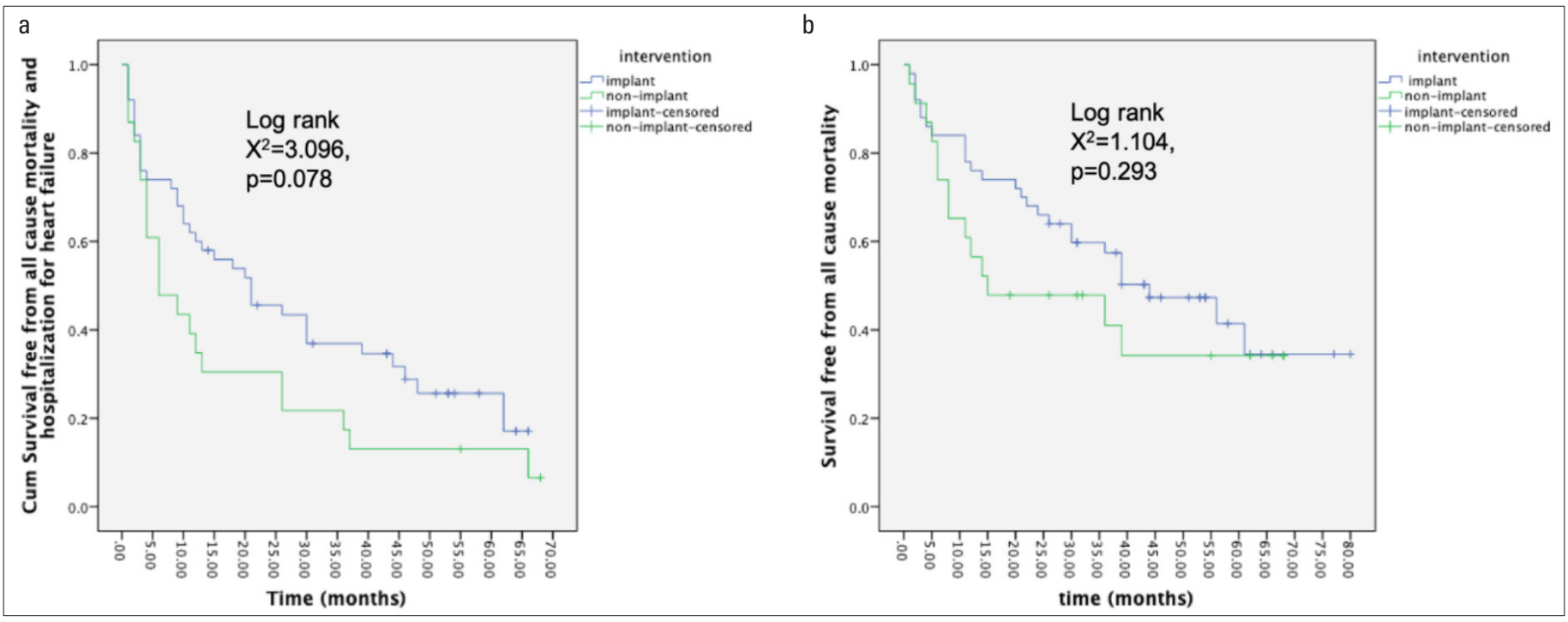

Figure 3. (a, b) Kaplan Meier analysis of survival free from all-cause mortality and hospitalization for heart failure during follow-up

\begin{tabular}{|c|c|c|c|}
\hline Variables & Successful implantation (50) & Non-implanted (23) & $P$-value \\
\hline Age, mean (SD), years & $67.5( \pm 9.3)$ & $65.6( \pm 13.2)$ & 0.488 \\
\hline \multicolumn{4}{|l|}{ NYHA functional class ( $\mathrm{n}, \%$ ) } \\
\hline- III & $39(78.0)$ & 18 (78.2) & 0.980 \\
\hline Ischemic etiology to HF (n, \%) & $31(62.0)$ & $17(73.0)$ & 0.097 \\
\hline Diabetes mellitus (n, \%) & $20(40.0)$ & $10(43.4)$ & 0.803 \\
\hline Hypertension (n, \%) & $48(96.0)$ & $22(95.6)$ & 0.945 \\
\hline Hyperlipidemia (n, \%) & $29(58.0)$ & $16(69.5)$ & 0.396 \\
\hline Anemia existence $(n, \%)^{* *}$ & $10(20.0)$ & $3(13.0)$ & 0.470 \\
\hline \multicolumn{4}{|l|}{ Medications, n (\%) } \\
\hline - Diuretics & $50(100.0)$ & $23(100.0)$ & NS \\
\hline - ACE inhibitor/ARB & $47(94.0)$ & $22(95.6)$ & 0.773 \\
\hline - $\beta$-Blocker/ivabradin & $49(98.0)$ & $23(100.0)$ & 0.495 \\
\hline CRT eligible (n, \%) & $8(16.0)$ & $4(17.3)$ & 0.882 \\
\hline
\end{tabular}

$\mathrm{p}=0.078$ ) (Fig. 3a). Cox regression analysis in which age [hazard ratio $(\mathrm{HR})=1.0,95 \% \mathrm{Cl}: 0.97-1.02, \mathrm{p}=0.774)$ and $\operatorname{sex}(\mathrm{HR}=0.91,95 \%$ $\mathrm{Cl}: 0.53-1.57, p=0.752)$ were included in addition to the intervention status ( $\mathrm{HR}=1.60,95 \% \mathrm{Cl}$ : 0.924-2.77, $\mathrm{p}=0.093$ ) showed that none of these variables affected the combined endpoint. Similarly, successful implantation had higher survival time free from all-cause mortality than the non-implant group (44.0 months;
95\% Cl: 25.8 vs. 62.2 months and 15.0 months; $95 \% \mathrm{Cl}: 0.1$ to 46.6 months, respectively) but this difference was not significant either $\left(\chi^{2}=1.104, p=0.293\right)$ (Fig. 3b). Cox regression analysis in which age ( $\mathrm{HR}=1.02,95 \% \mathrm{Cl}: 0.99-1.05, \mathrm{p}=0.275)$ and $\operatorname{sex}(\mathrm{HR}=1.12$, 95\% Cl: 0.58-2.16, $\mathrm{p}=0.741)$ were included in addition to the intervention status ( $\mathrm{HR}=1.42,95 \% \mathrm{Cl}: 0.74-2.73, \mathrm{p}=0.296)$ showed that none of these variables affected the combined endpoint. 


\begin{tabular}{|lccc|}
\hline \multicolumn{4}{|c|}{ Table 2. Baseline echocardiographic parameters of the population } \\
\hline Variables & $\begin{array}{c}\text { Successful } \\
\text { implantation (50) }\end{array}$ & $\begin{array}{c}\text { Non-implanted } \\
\text { (23) }\end{array}$ & P-value \\
\hline EF (\%) & $26.6 \pm 10.5$ & $28.4 \pm 9.9$ & 0.520 \\
EDV (mL) & $200.3 \pm 47.6$ & $212.3 \pm 72.2$ & 0.482 \\
ESV (mL) & $156.7 \pm 34.6$ & $163.0 \pm 64.5$ & 0.682 \\
LVEDD (mm) & $65.2 \pm 7.8$ & $66.7 \pm 9.3$ & 0.501 \\
LVESD (mm) & $53.4 \pm 9.6$ & $55.0 \pm 11.6$ & 0.582 \\
MR grade & $3.5 \pm 0.5$ & $3.4 \pm 0.6$ & 0.705 \\
Vena contracta (mm) & $8.5 \pm 1.6$ & $8.7 \pm 1.7$ & 0.715 \\
LA diameter (mm) & $52.9 \pm 12.4$ & $53.1 \pm 7.3$ & 0.970 \\
\hline EDV - end-diastolic volume; EF - ejection fraction; ESV - end-systolic volume; LA - left \\
atrium; LVEDD - left ventricular end-diastolic dimension; LVESD - left ventricular end- \\
systolic dimension; MR - mitral regurgitation \\
\hline
\end{tabular}

Table 3. Pre-procedural and post-procedural echocardiographic parameters of the implantation group

\begin{tabular}{|c|c|c|c|}
\hline $\begin{array}{l}\text { Implantation } \\
\text { group }\end{array}$ & $\begin{array}{l}\text { Pre-procedural } \\
\text { (n) }\end{array}$ & $\begin{array}{c}\text { Post-procedural } \\
\text { (n) }\end{array}$ & $P$-value \\
\hline $\mathrm{EF}(\%)$ & $26.6 \pm 10.5$ & $29.8 \pm 9.7$ & 0.000 \\
\hline EDV (ml) & $200.3 \pm 47.6$ & $199.8 \pm 45.6$ & 0.899 \\
\hline ESV (ml) & $156.7 \pm 34.6$ & $153.54 \pm 32.7$ & 0.297 \\
\hline LVEDD (mm) & $65.2 \pm 7.8$ & $64.5 \pm 9.5$ & 0.545 \\
\hline LVESD (mm) & $53.4 \pm 9.6$ & $51.4 \pm 8.2$ & 0.003 \\
\hline MR grade & $3.5 \pm 0.5$ & $2.4 \pm 0.6$ & 0.000 \\
\hline Vena contracta $(\mathrm{mm})$ & $8.5 \pm 1.6$ & $5.5 \pm 1.6$ & 0.000 \\
\hline LA diameter (mm) & $52.9 \pm 12.4$ & $53.0 \pm 10.9$ & 0.954 \\
\hline
\end{tabular}

EDV - end-diastolic volume; EF - ejection fraction; ESV - end-systolic volume; LA - left atrium; LVEDD - left ventricular end-diastolic dimension; LVESD - left ventricular endsystolic dimension; MR - mitral regurgitation

None of the patients underwent CRT implantation during hospital stay of the Carillon procedure. Twelve patients had CRT implanted at our institution (eight and four patients in the implanted and non-implanted groups, respectively) $(16.0 \%$ vs. $17.3 \% \mathrm{p}=0.157)$.

\section{Discussion}

The result of this retrospective analysis showed that in "inoperable" patients with severe HF and FMR, CS-based Carillon Mitral Contour System implantation decreased composite endpoint of all-cause mortality and HF hospitalization compared with similar patients in whom the device was not able to be implanted for anatomic and technical reasons, although the difference was not significant. In addition, implantation of the device was safe with extremely low rate of major complications.

The Carillon Mitral Contour System is an alternate and less invasive indirect mitral annuloplasty procedure with a high safety profile, mainly for secondary MR. Previous reports have shown a benefit with the Carillon device for correction of MR, improvement in left ventricular volumes, and better functional status for patients at 12 months. However, these studies were not randomized, controlled trials with smaller study populations until the REDUCE-FMR trial results were published. Unlike the MitraClip device, there is no recommendation of the Carillon Mitral Contour System for percutaneous correction of secondary MR in the current guidelines. Although the American Heart Association/American College of Cardiology has just addressed percutaneous edge-to-edge repair procedures in a focused update for patients with HF and with FMR; in ESC guidelines, these methods took place with Class IIb recommendation $(7,8)$.

In this study, we used CS -based indirect mitral annuloplasty system in patients who were deemed "inoperable" by the heart team. The reason of this strategy was a result of the National Security Systems policy in which Carillon System is reimbursed only in patients with "inoperable" severe FMR and HF with reduced ejection fraction.

Thus, compared with the populations in AMADEUS, TITAN $\mathrm{I}-\mathrm{II}$, and REDUCE-FMR trials, our patients were more fragile with lower ejection fraction around $25 \%$, more symptomatic with at least NYHA class $3 \mathrm{HF}$, and had worse MR with $3+$ or greater (9-12). Three of our patients had severe renal insufficiency (creatinine $>2.2 \mathrm{mg} / \mathrm{dL}$ ), and one of our patients had a history of using inotropic support within the prior 30 days, which were accepted as exclusion criteria in the former trials. The clinical situation of our study populations was worse than advised previously (13). Considering that both the groups were receiving optimal medical therapy, the lower rates of both primary endpoint and all-cause mortality, although insignificant, may be important. One potential reason could be that the potential benefit of percutaneous mitral valve annuloplasty might be reduced in this population with severe disease. MITRA-FR and COAPT trials showed that the effectiveness of the MitraClip device was more prominent in patients with better clinical status than in patients close to end-stage heart disease (14). In fact, the MitraClip device in MITRA-FR and COAPT trials presented controversial results regarding the clinical endpoints. In MITRA$F R$ the difference in composite primary endpoint for all-cause mortality and HF hospitalization was not significant between the MitraClip and control groups at 12 months ( $54.6 \%$ vs. $51.3 \%$ ) and 24 months $(63.8 \%$ vs. $65.4 \%)(15,16)$. Conversely, in COAPT, MitraClip implantation led to a significant reduction in the primary endpoint of HF hospitalization at 24 months versus medical therapy alone $(35.8 \%$ vs. $67.9 \%$ per-patient year, $p<0.001)$, and this superiority was maintained at 36 months for the primary outcome of death/HF hospitalization ( $58.8 \%$ vs. $88 \%, \mathrm{p}<0.001)(17$, 18). The major explanations of this difference were the presence of higher NYHA class and LV end-diastolic volume index values in the MITRA-FR study. The rate of NYHA Class III and IV patients in MITRA-FR and COAPT trials were 58.5 and $8.6 \%$ and 52.5 and 8.3 , respectively. This study consisted of $57(78.1 \%)$ NYHA class III and 16 (21.9\%) NYHA class IV patients, showing clearly the worse clinical condition of the patient population in our study. It has been shown that patients with NYHA class IV symptoms have one-year mortality as high as $75 \%$ with a significantly higher risk of dying of progressive HF (19). 
This study's non-randomized design and small number of patients which makes it a potential underpowered study, are the other explanations for the lack of insignificance. However, the Carillon Mitral Contour System may be ineffective, especially in patients with extremely severe disease. FMR is the result instead of being the reason for underlying cardiomyopathy, and secondary MR may be only a marker of illness severity in contrast to primary MR.

The control group of this study included patients in whom the device was not implanted because of anatomic and technical reasons. The rate of non-implantation $(68.5 \%)$ was similar to other controlled studies (63\% in AMADEUS, $68 \%$ in TITAN I, 83\% in TITAN II, and 84\% in REDUCE-FMR) which enrolled 36 to 120 patients (9-12). There were two main reasons for failed implantations in our study; unsuitable CS anatomy and coronary artery compromise. Part of the evaluation for the suitability of the CarilIon device includes invasive measurements of the CS/great cardiac vein preferably with venous angiogram (12). Two $(4.2 \%)$ patients in AMADEUS, four (6.2\%) patients in TITAN, two (2.9\%) patients in TITAN II, and two patients $(2.2 \%)$ in REDUCE-FMR were found to have unsuitable venous anatomy for the Carillon Mitral Contour System after venography was performed (9-12). In our study, eleven (15.1\%) patients had inappropriate venous anatomy for the procedure. Although computed tomography imaging was a part of AMADEUS as procedural planning for assessing vein suitability, such imaging was not found to be suitable to replace invasive venography and abandoned in the subsequent trials (9). However, coronary artery compromise, mostly because of the circumflex artery and rarely distal right coronary artery branches, is almost impossible to forecast preprocedurally. Nine $(12.3 \%)$ of our patients had failure because of circumflex artery compression. This proportion was similar to that of AMADEUS (10 patients; 20.1\%), TITAN (eight patients; $15.1 \%$ ), TITAN II (seven patients; 19.4\%), and REDUCE-FMR (eight patients; 9.6\%) studies which reported implantation failure because of coronary compromise (9-12). Only one of our patients died in the first 30-day follow-up because of intraprocedural CS perforation and cardiac tamponade, whereas the other two patients with CS perforation were managed successfully with pericardiocentesis. Similar to the previous studies, this study also demonstrated that implantation of Carillon device is technically safe.

\section{Study limitations}

There were several limitations of this study. First, it was a non-randomized retrospective study. The lack of randomization is important; however, the factors causing non-implantation do not relate to better or worse clinical outcomes. The criteria for the decision for implantation of the Carillon device was clearly stated in the regulations of reimbursement system; therefore, this may diminish the downside of non-randomization to some extent. In addition, the baseline characteristics of the two groups were similar. Second, this was a single center study, but our center is very experienced in the intervention of structural heart disease which prevented the drawbacks of the learning curve. Third, the echocardiographic parameters were not collected systematically and during the course of follow-up. We could only compare short-term (in-hospital) changes in these parameters and could not define the improvement or progression in MR as well as left ventricular function. However, we could track the hard clinical endpoints, that is, all-cause mortality and HF hospitalizations, which are more important in the decision of management policy of these patients. Fourth, we were not aware of the number of patients who underwent CRT/ ICD implantation or the impact of it on mortality. Twelve patients who were being followed up by our center underwent CRT implantation at least three months after the index procedure.

\section{Conclusion}

Carillon Mitral Contour System implantation seems to decrease mortality and HF hospitalizations in patients with severe HF and FMR and deemed "inoperable" because of extreme surgical risk. Further prospective, sham-controlled studies are required to validate its effects on hard clinical endpoints and to compare this method with other catheter-based approaches.

Conflict of interest: None declared.

Peer-review: Externally peer-reviewed.

Author contributions: Concept - S.A.; Design - E.Y.; Supervision Y.G., B.B., A.S.Y., H.K.K.; Fundings - None; Materials - S.G. H.T., M.K.; Data collection \&/or processing - S.G. H.T., M.K.; Analysis \&/or interpretation - S.F.; Literature search - M.Ç., U.Ç.Y.; Writing - S.Y.; Critical review - C.B.

\section{References}

1. Trichon $\mathrm{BH}, \mathrm{O}^{\prime}$ Connor $\mathrm{CM}$. Secondary mitral and tricuspid regurgitation accompanying left ventricular systolic dysfunction: is it important, and how is it treated? Am Heart $\mathrm{J} 2002$; 144: 373-6. [Crossref]

2. Junker A, Thayssen P, Nielsen B, Andersen PE. The hemodynamic and prognostic significance of echo-Doppler-proven mitral regurgitation in patients with dilated cardiomyopathy. Cardiology 1993; 83: 14-20. [Crossref]

3. Kalaria VG, Passannante MR, Shah T, Modi K, Weisse AB. Effect of mitral regurgitation on left ventricular thrombus formation in dilated cardiomyopathy. Am Heart J 1998; 135: 215-20. [Crossref]

4. Schmitto JD, Lee LS, Mokashi SA, Bolman RM 3rd, Cohn LH, Chen FY. Functional mitral regurgitation. Cardiol Rev 2010; 18: 285-91. [Crossref]

5. Raja SG, Berg GA. Moderate ischemic mitral regurgitation: to treat or not to treat? J Card Surg 2007; 22: 362-9. [Crossref]

6. Krishnaswamy A, Marc Gillinov A, Griffin BP. Ischemic mitral regurgitation: pathophysiology, diagnosis, and treatment. Coron Artery Dis 2011; 22: 359-70. [Crossref]

7. Bonow RO, O'Gara PT, Adams DH, Badhwar V, Bavaria JE, Elmariah S, et al. 2020 Focused Update of the 2017 ACC Expert Consensus Decision Pathway on the Management of Mitral Regurgitation: A Report of the American College of Cardiology Solution Set Oversight Committee. J Am Coll Cardiol 2020; 75: 2236-70. [Crossref] 
8. Vahanian A, Alfieri 0, Andreotti F, Antunes MJ, Barón-Esquivias G, Baumgartner $\mathrm{H}$, et al.; Joint Task Force on the Management of Valvular Heart Disease of the European Society of Cardiology (ESC); European Association for Cardio-Thoracic Surgery (EACTS). Guidelines on the management of valvular heart disease (version 2012). Eur Heart J 2012; 33: 2451-96. [Crossref]

9. Schofer J, Siminiak T, Haude M, Herrman JP, Vainer J, Wu JC, et al. Percutaneous mitral annuloplasty for functional mitral regurgitation: results of the CARILLON Mitral Annuloplasty Device European Union Study. Circulation 2009; 120: 326-33. [Crossref]

10. Siminiak T, Wu JC, Haude M, Hoppe UC, Sadowski J, Lipiecki J, et al. Treatment of functional mitral regurgitation by percutaneous annuloplasty: results of the TITAN Trial. Eur J Heart Fail 2012; 14: 931-8. [Crossref]

11. Lipiecki J, Siminiak T, Sievert H, Müller-Ehmsen J, Degen H, Wu JC, et al. Coronary sinus-based percutaneous annuloplasty as treatment for functional mitral regurgitation: the TITAN II trial. Open Heart 2016; 3: e000411. [Crossref]

12. Witte KK, Lipiecki J, Siminiak T, Meredith IT, Malkin CJ, Goldberg SL, et al. The REDUCE FMR Trial: A Randomized Sham-Controlled Study of Percutaneous Mitral Annuloplasty in Functional Mitral Regurgitation. JACC Heart Fail 2019; 7: 945-55. [Crossref]

13. Rottländer D, Degen $H$, Haude $M$. The Carillon: strategies for optimal patient selection and optimised results. Eurolntervention 2016; 12: Y64-6. [Crossref]
14. Pibarot P, Delgado V, Bax JJ. MITRA-FR vs. COAPT: lessons from two trials with diametrically opposed results. Eur Heart J Cardiovasc Imaging 2019; 20: 620-4. [Crossref]

15. Obadia JF, Messika-Zeitoun D, Leurent G, lung B, Bonnet G, Piriou N, et al.; MITRA-FR Investigators. Percutaneous Repair or Medical Treatment for Secondary Mitral Regurgitation. N Engl J Med 2018; 379: 2297-306. [Crossref]

16. lung $B$, Armoiry $X$, Vahanian A, Boutitie F, Mewton N, Trochu JN, et al.; MITRA-FR Investigators. Percutaneous repair or medical treatment for secondary mitral regurgitation: outcomes at 2 years. Eur $\mathrm{J}$ Heart Fail 2019; 21: 1619-27. [Crossref]

17. Stone GW, Lindenfeld J, Abraham WT, Kar S, Lim DS, Mishell JM, et al.; COAPT Investigators. Transcatheter Mitral-Valve Repair in Patients with Heart Failure. N Engl J Med 2018; 379: 2307-18. [Crossref]

18. Mack MJ, Abraham WT, Lindenfeld J, Stone GW; On behalf of the COAPT Investigators. Three-Year outcomes from a randomized trial of transcatheter mitral valve leaflet approximation in patients with heart failure and secondary mitral regurgitation. In: TCT. San Francisco, CA, 2019.

19. Arnold JM, Liu P, Demers C, Dorian P, Giannetti N, Haddad H, et al.; Canadian Cardiovascular Society. Canadian Cardiovascular Society consensus conference recommendations on heart failure 2006: diagnosis and management. Can J Cardiol 2006; 22: 23-45. [Crossref] 